\title{
Editorial: Magnetic Records of Extreme Geological Events
}

\author{
Eric Font ${ }^{1 *}$, Alexandra Abrajevitch ${ }^{2}$ and Fabio Florindo ${ }^{3}$ \\ ${ }^{1}$ Faculdade de Ciências, Instituto Dom Luís, Universidade de Lisboa, Lisboa, Portugal, ${ }^{2}$ Institute of Tectonics and \\ Geophysics, Russian Academy of Sciences, Khabarovsk, Russia, ${ }^{3}$ Istituto Nazionale di Geofisica e Vulcanologia, Rome, Italy
}

Keywords: magnetism, geology, extreme events, geosciences, earth sciences

\section{The Editorial on the Research Topic}

\section{Magnetic Records of Extreme Geological Events}

The normal evolution of the Earth has been punctuated in the past by sudden, dramatic events. Changes in the Earth's rotational speed, asteroid impacts, violent volcanic eruptions, earthquakes, tsunami, and extreme climatic events have periodically caused changes in the environment, which often harmed dominant life forms, but also triggered rapid biotic evolution by opening up many new ecological niches. Changes in sedimentation patterns and redox conditions that accompany catastrophic events affect accumulation, formation and alteration of magnetic minerals in rocks, and thus leave evidence in the geologic record. This E-Book is derived from the Frontiers in Geomagnetism and Paleomagnetism Research Topic entitled "Magnetic Records of Extreme Geological Events." Nine contributions included in this book adopt very different approaches to answer the varied and complex research challenges related to the study of the past catastrophic events.

Two contributions to this Research Topic discuss high energy fluvial events. Building on their previous extensive experience in studies of historical high-energy flooding events in the region, Wassmer et al. present reconstruction of the flooding characteristics during the $4220 \mathrm{BP}$ paleotsunami event in North Sumatra. In addition to classical sedimentological analysis, the authors used the Anisotropy of Magnetic Susceptibility (AMS) technique to assess flow direction that prevailed during sediment emplacement. Information gathered about orientation, energy and flow patterns over the coastal plain have demonstrated similar behavior of the $4220 \mathrm{BP}$ and the historical 2004 tsunami events. The possibility of using rock magnetic techniques for dating high energy fluvial events is discussed by Muxworthy et al. The authors used unblocking temperatures of viscous remanent magnetization (VRM) in erratics associated with three large flood events to estimate the timing of block rotations. Their findings suggest that the VRM dating method works the best for recent events $(<2-3 \mathrm{ka})$ where the ambient temperature history can be constrained, while age estimates of older events have greater uncertainty.

The next two contributions to this Research Topic are broadly related to understanding geologic signatures of asteroid impacts. In their original research article, Kubo et al. investigated the cause of the anomalously strong natural remanent magnetization observed in shocked granitic rocks in the crystalline core of the Vredefort crater-the largest and oldest (2023 $\pm 4 \mathrm{Ma})$ known terrestrial impact structure. The authors found that coarse magnetite grains are subdivided by hematite lamellae creating striped magnetic domains, and attributed the strong remanence primarily to this unusual domain structure, which formed as the result of post-impact high-temperature metamorphic alteration of shock-strained magnetic grains. Later terrestrial lightning strikes on the partially oxidized magnetite may have also intensified the remanence. In the mini-review article, Font and Abrajevitch discussed two competitive explanations, volcanism vs. asteroid impact, for the decrease in magnetic susceptibility values in the sediments just below the Cretaceous-Paleogene 
boundary. Based on environmental proxy records from two reference sections, Bidart (France) and Gubbio (Italy), the authors suggested that the evidence for dissolution of ferrimagnetic minerals accompanied with the presence of akaganeite, an unusual mineral phase in marine sediments, is best explained by an ocean acidification and aerosol deposition event linked to the Deccan Phase-2 volcanism.

Another two contributions to this Research Topic are related to studies of geomagnetic reversals. In addition to their use for dating and correlation, high resolution records of the transitional field behavior provide key constraints on the working of the geodynamo. In their original research article, Soler-Arechalde et al. presented a record of the Matuyama-Brunhes geomagnetic reversal obtained from the tephra-paleosol sedimentary sequence of Tlaxcala (Central Mexico). The authors demonstrated the primary origin of the magnetic remanence and suggested that paleosol sequences can provide good high resolution records of the geomagnetic magnetic field during geomagnetic reversals. In the following Perspective article, Pacca et al. analyzed the geomagnetic reversal frequency rates over the past $510 \mathrm{Myr}$ and noted that the reversal frequency correlates with the Earth's rotation changes, as well as with the $\delta^{18} \mathrm{O}$ oscillations, which reflect the glacial and interglacial periods. The authors hypothesized that the $\delta^{18} \mathrm{O}$ oscillations it can be used as a possible indicator to explain the length of day variations and the associated changes in the geodynamo regime.

The last contributions to this Research Topic are broadly related to oxygenation events in the Earth history. Carlut et al. presented a study of the Late Archean Boolgeeda Banded Iron Formation (Western Australia), the association of which with free oxygen derived from oxygenic photosynthesis has long been recognized. The authors report the presence of two distinct populations of magnetite characterized by different Verwey transition temperatures, within a $2 \mathrm{~m}$ thick sedimentary section.
They argue that secondary silicon-rich magnetite characterized by the low Verwey transition temperature can be linked to biological activity, and may thus be a potential biomarker.

Based on the presence of hematite, taken as the evidence for high oxygen fugacity during formation of the $780 \mathrm{Ma}$ old subduction-associated rocks that are now outcropping in the Arabic peninsula, Macouin et al. hypothesize that the Neoproterozoic Oxygenation Event may have been triggered by multi-million years oxic volcanic emissions during a protracted period at the end of the Neoproterozoic when continents were assembled in the Rodinia supercontinent. In a short commentary paper, Nédélec and Borisova questioned the primary origin of the hematite identified by Macouin et al. in the granites and argued against the contribution of the associated magmas in the Neoproterozoic Oxygenation Event. In their response, Macouin et al. provide new arguments defending the primary origin of hematite.

Collectively, the articles in this Research Topic represent an interesting range of opinions, reviews, and original studies that contribute to understanding the role of catastrophic events in the Earth history. We hope you enjoy this eclectic mix.

\section{AUTHOR CONTRIBUTIONS}

\section{EF, AA, and FF wrote the editorial text.}

Conflict of Interest Statement: The authors declare that the research was conducted in the absence of any commercial or financial relationships that could be construed as a potential conflict of interest.

Copyright (C) 2016 Font, Abrajevitch and Florindo. This is an open-access article distributed under the terms of the Creative Commons Attribution License (CC BY). The use, distribution or reproduction in other forums is permitted, provided the original author(s) or licensor are credited and that the original publication in this journal is cited, in accordance with accepted academic practice. No use, distribution or reproduction is permitted which does not comply with these terms. 